\title{
Chemistry of Glycine on Pd(111): Temperature-Programmed Desorption and X-ray Photoelectron Spectroscopic Study
}

\author{
Feng Gao, Zhenjun Li, Yilin Wang, Luke Burkholder, and W. T. Tysoe* \\ Department of Chemistry and Biochemistry, and Laboratory for Surface Studies, University of Wisconsin- \\ Milwaukee, Milwaukee, Wisconsin 53211
}

Received: March 9, 2007; In Final Form: May 7, 2007

\begin{abstract}
The surface chemistry of glycine is studied on clean $\mathrm{Pd}(111)$ using a combination of X-ray photoelectron spectroscopy (XPS) and temperature-programmed desorption (TPD). Glycine adsorbs strongly into second and subsequent layers as well as on the first monolayer, where the first-layer coverage is measured by titrating the bare surface with carbon monoxide. A small portion of glycine adsorbed directly on the $\operatorname{Pd}(111)$ surface desorbs as intact molecules, whereas the majority thermally decomposes by $\mathrm{C}-\mathrm{C}$ bond scission. The $\mathrm{COO}$ moiety desorbs as $\mathrm{CO}$ and $\mathrm{CO}_{2}$, whereas the nitrogen-containing fragment yields methylamine and $\mathrm{HCN}$. XPS reveals that glycine adsorbs predominantly in its zwitterionic form on the clean surface, whereas the multilayer contains $70-80 \%$ zwitterionic glycine, the remainder adsorbing in the neutral form.
\end{abstract}

\section{Introduction}

The study of $\alpha$-amino acids, the building blocks of proteins, on surfaces is relevant to a number of areas such as the creation of biocompatible surfaces or for the functionalization of scanning probe tips to explore biochemical interactions. These molecules are generally chiral-the exception being glycine, the subject of this paper. However, since it is the simplest amino acid, it is the easiest to understand and will act as a basis for exploring more complex amino acids.

We have shown previously that enantioselective chemisorption can be observed on $\operatorname{Pd}(111)$ in ultrahigh vacuum (UHV) through chiral modification of the surface using $(R)$ - or $(S)$-2butanol, where enhanced chemisorption of propylene oxide with the same chirality as the 2-butanol modifier was found over a rather narrow 2-butanol coverage range. ${ }^{1}$ More recently, similar behavior was found on $\operatorname{Pt}(111) .^{2}$ A $\operatorname{Pd}(111)$ surface modified by chiral 2-methyl butanoic acid displays no enantioselective chemisorption. However, when chiral 2-amino butanoic acid was used as a modifier, enantioselectivity was restored. It was proposed that freer azimuthal rotation of the chiral center in 2-methyl butanoate results in a loss of enantioselectivity, while an amino group anchors the chiral center to the surface resulting in less mobility of the modifier, thus restoring enantioselectivity. ${ }^{3}$ It is therefore rather clear that the geometry of the chiral modifier plays an important role in defining the extent of enantioselective chemisorption. In order to gain a better understanding of the adsorption of $\alpha$-amino acids on $\operatorname{Pd}(111)$ and probe their chemical stability, we report here on the surface chemistry of the simplest amino acid, glycine, on $\operatorname{Pd}(111)$. Although glycine is itself not chiral, as the simplest amino acid, it is an ideal starting point for understanding more structurally complicated chiral $\alpha$-amino acids. The adsorption of glycine has been studied on a number of metal single-crystal surfaces including $\mathrm{Cu},{ }^{4-10} \mathrm{Au},{ }^{11-13} \mathrm{Ag},{ }^{14,15} \mathrm{Pt},{ }^{16,17}$ and binary metal surfaces, $\mathrm{NiAl}(110),{ }^{18} \mathrm{Ag} / \mathrm{Cu}(001)$, and $\mathrm{Ag} / \mathrm{Cu}(111),{ }^{19}$ and $\mathrm{Cu} /$ $\mathrm{Au}(111) .{ }^{20}$ It should be mentioned that the techniques applied

* Author to whom correspondence should be addressed. Phone: (414) 229-5222. Fax: (414) 229-5036. E-mail: wtt@uwm.edu. in the current report, namely, temperature-programmed desorption (TPD) and X-ray photoelectron spectroscopy (XPS), do not allow us to gain detailed understanding of the adsorption geometry of glycine on the surface. Nevertheless, they provide important information on the stability and coverages of amino acids on metal surfaces as a basis for understanding their enantioselectivity.

\section{Experimental Section}

Temperature-programmed desorption data were collected in a UHV chamber operating at a base pressure of $8 \times 10^{-11}$ torr that has been described in detail elsewhere, ${ }^{21}$ where desorbing species were detected using a Dycor quadrupole mass spectrometer placed in line of sight of the sample. The temperature ramp and data collection were controlled using LabView software. This chamber was also equipped with a double-pass cylindrical mirror analyzer for Auger spectroscopy measurements, primarily used to monitor sample cleanliness, and an ion-sputtering source for sample cleaning.

X-ray photoelectron spectra were collected in another chamber operating at a base pressure of $2 \times 10^{-10}$ torr, which was equipped with a Specs X-ray source and double-pass cylindrical mirror analyzer. Spectra were typically collected with a $\mathrm{Mg} \mathrm{K} \alpha$ $\mathrm{X}$-ray power of $250 \mathrm{~W}$ and an analyzer pass energy of $50 \mathrm{eV}$. The binding energies were calibrated using the $\mathrm{Pd} 3 \mathrm{~d}_{5 / 2}$ feature of clean $\mathrm{Pd}(111)$ at $334.8 \mathrm{eV}$ as a standard. Temperaturedependent XP spectra were collected by heating the sample to the indicated temperature for $5 \mathrm{~s}$, then allowing the sample to cool to $\sim 100 \mathrm{~K}$, following which the spectrum was recorded.

The $\operatorname{Pd}(111)$ substrate $(1 \mathrm{~cm}$ diameter, $0.5 \mathrm{~mm}$ thick) was cleaned using a standard procedure, which consisted of cycles of argon ion bombardment $\left(2 \mathrm{kV}, 1 \mu \mathrm{A} / \mathrm{cm}^{2}\right)$ and annealing in $4 \times 10^{-8}$ torr of $\mathrm{O}_{2}$ at $1000 \mathrm{~K} .{ }^{1}$ The cleanliness of the sample was judged using XPS and oxygen titration where $\mathrm{O}_{2}$ instead of $\mathrm{CO}$ desorbs following $\mathrm{O}_{2}$ adsorption when the sample is carbon free. Following each TPD or XPS experiment, the surface is briefly annealed once again in $\mathrm{O}_{2}$ to regain the cleanliness.

Glycine was adsorbed on the $\operatorname{Pd}(111)$ surface using a homebuilt Knudsen source, which was differentially pumped using 

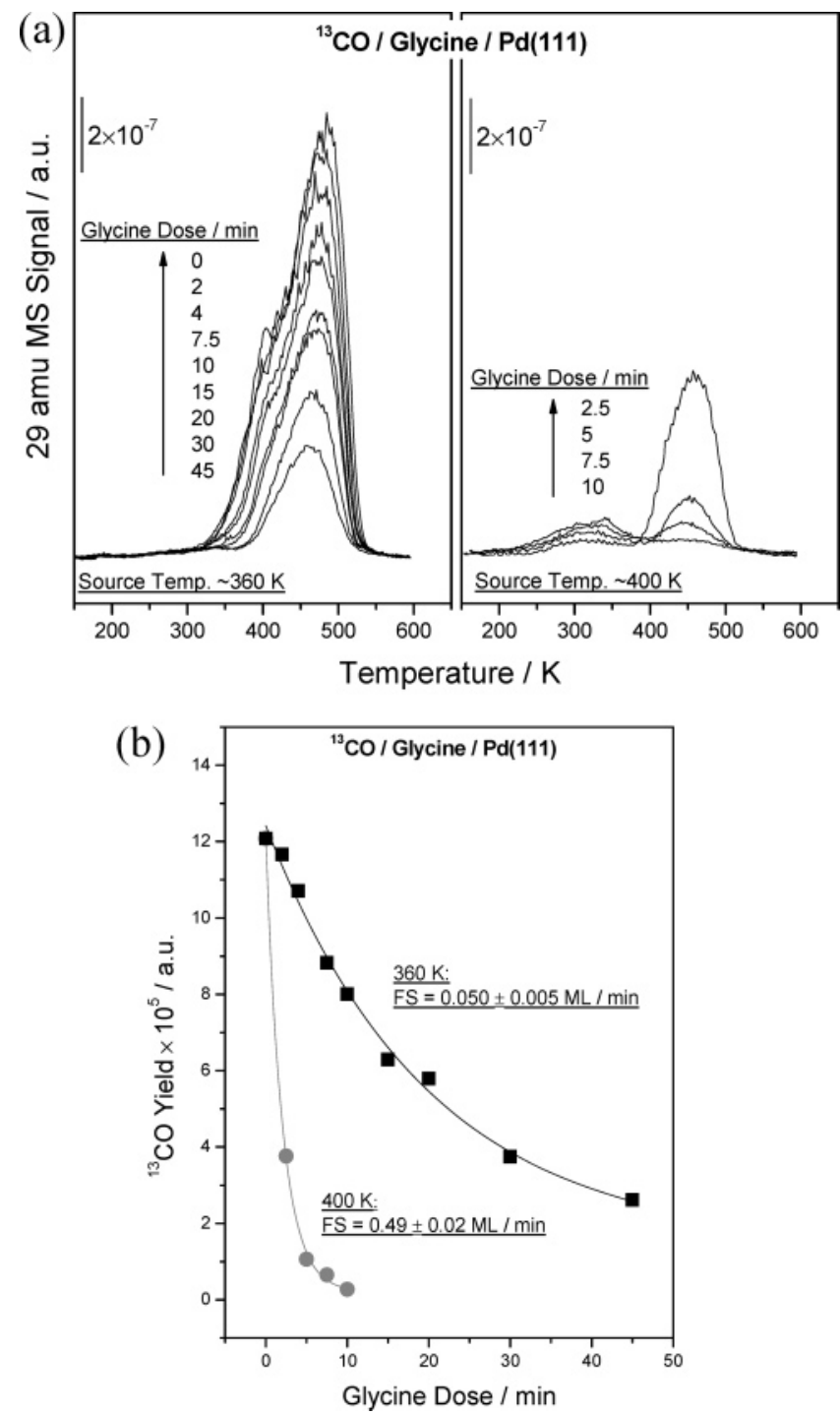

Figure 1. (a) ${ }^{13} \mathrm{CO}$ (29 amu) TPD profiles collected following exposure of $\operatorname{Pd}(111)$ surfaces dosed with glycine to $10 \mathrm{~L}\left(1 \mathrm{~L}=1 \times 10^{-6}\right.$ torr s) as a function of glycine dose in min for source temperatures of $\sim 360$ and $400 \mathrm{~K}$; (b) plots of the integrated $29 \mathrm{amu}\left({ }^{13} \mathrm{CO}\right)$ signal yield vs

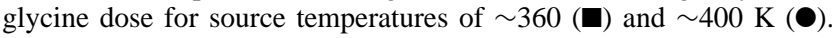
The solid lines are fits to the data (see text).

a turbomolecular pump. Glycine powder (Aldrich, 99\% purity) was stored in a stainless steel vial. The whole evaporation source was warmed by means of a heating tape, and the temperature was measured by a K-type thermocouple attached to the outer wall of the vial. Glycine was typically outgassed for at least $2 \mathrm{~h}$ at $400 \mathrm{~K}$ before adsorption. Glycine was dosed onto Pd(111) using a glass tube that was placed $\sim 1 \mathrm{~cm}$ from the sample to avoid contaminating other parts of the chamber. ${ }^{13} \mathrm{CO}$ (ISOTEC, $\geq 99 \%{ }^{13} \mathrm{C}$ ) was used as received.

\section{Results}

3.1. Glycine Coverage Measurements. The dosing rate of glycine onto $\mathrm{Pd}(111)$ is determined by means of CO titrations where the $\mathrm{CO}$ coverage was measured using TPD, taking advantage of the fact that $\mathrm{CO}$ selectively adsorbs on bare, but not glycine-covered, $\mathrm{Pd}(111)$. As will be shown below, $\mathrm{CO}$ forms during glycine decomposition so that ${ }^{13} \mathrm{CO}$ is used for this purpose. Figure 1a displays desorption profiles of ${ }^{13} \mathrm{CO}$ (at $29 \mathrm{amu}$ ) as a function of glycine dosing time. Both glycine and ${ }^{13} \mathrm{CO}$ were adsorbed at a $\mathrm{Pd}(111)$ sample temperature of $250 \mathrm{~K}$ to avoid background water adsorption. An amount of $10 \mathrm{~L}$ ( $1 \mathrm{~L}=10^{-6}$ torr $\left.\mathrm{s}\right)$ of ${ }^{13} \mathrm{CO}$ was used to achieve a saturation $\mathrm{CO}$ coverage. Two sets of experiments were performed with glycine dosing source temperatures of $\sim 360$ and $\sim 400 \mathrm{~K}$. On clean $\mathrm{Pd}(111)$, a broad CO desorption state was found between 250 and $550 \mathrm{~K}$ that comprised two features: a major desorption peak centered at $\sim 460 \mathrm{~K}$ and a shoulder below $400 \mathrm{~K}$. Previous studies have shown that the higher-temperature feature is due to $\mathrm{CO}$ adsorption on bridge and threefold hollow sites, whereas the low-temperature state is due to adsorption on atop sites. ${ }^{22}$ The ${ }^{13} \mathrm{CO}$ coverage decreases on the glycine-covered surfaces as expected. The integrated ${ }^{13} \mathrm{CO}$ desorption peak areas are plotted in Figure $1 \mathrm{~b}$ as a function of glycine dose for the two source temperatures used for these experiments. This also indicates the corresponding glycine dosing rates at these two source temperatures, and in the following, all glycine doses are converted to coverages (in ML). Details of the dosing rate calculation are presented in the Discussion section.

3.2. Low-Temperature Adsorption of Glycine: XPS Measurements. Figure 2a displays the Pd 3d XPS spectral region versus glycine coverage where the $\mathrm{Pd}$ single crystal is maintained at $100 \mathrm{~K}$ during glycine adsorption and data collection. As expected, the Pd signal intensity decreases with increasing glycine coverage. Note that the binding energy of Pd itself does not vary, suggesting that the adsorption of glycine does not noticeably modify the electronic structure of the Pd substrate. Figure $2 \mathrm{~b}$ plots the $\mathrm{Pd} 3 \mathrm{~d}_{5 / 2}$ signal intensity as a function of glycine coverage. It is found that the Pd signal intensity decreases almost linearly up to a coverage of $3 \mathrm{ML}$ of glycine and decreases more slowly thereafter.

Shown in Figure $3 \mathrm{a}$ is the corresponding $\mathrm{C} 1 \mathrm{~s}$ spectral region as a function of glycine coverage. Each spectrum can be readily resolved into two peaks, which are fit to Lorentzian profiles. The lower binding energy feature is assigned to the $\alpha$-carbon, whereas the high binding energy peak is assigned to the carboxylate group carbon. ${ }^{17}$ Figure $3 \mathrm{~b}$ plots the binding energies of the two $\mathrm{C} 1 \mathrm{~s}$ features as a function of glycine coverage. It is found that below $3 \mathrm{ML}$, both $\mathrm{C} 1 \mathrm{~s}$ binding energies increase rapidly and linearly with increasing coverage. Above $3 \mathrm{ML}$, a further, but much slower, linear binding energy increase is observed. The clear break at $3 \mathrm{ML}$ coverage confirms the precision of the glycine coverage calibration made using $\mathrm{CO}$ titrations since such binding energy variations as a function of glycine coverage have been found previously on other metal surfaces ${ }^{17}$ and will be discussed in more detail below.

Figure 4a displays the corresponding spectra of the $\mathrm{N} 1 \mathrm{~s}$ region. Two $\mathrm{N}$ 1s features are resolved for each spectrum, and the spectra are again fit using Lorentzian profiles. The higher binding energy peak is assigned to nitrogen in an $-\mathrm{NH}_{3}{ }^{+}$group (zwitterionic glycine), and the lower binding energy feature is assigned to nitrogen in $-\mathrm{NH}_{2}$ groups (neutral glycine and/or glycinate). ${ }^{17,20}$ By measuring the integrated areas of the spectra of these two species, it is found that $\sim 80 \%$ of adsorbed glycine stays in the zwitterionic form below $3 \mathrm{ML}$, decreasing to $\sim 70 \%$ at the highest coverage $(13.5 \mathrm{ML})$. Figure $4 \mathrm{~b}$ plots the $\mathrm{N} 1 \mathrm{~s}$ binding energy variation versus glycine coverage. These display very similar behavior to the $\mathrm{C} 1 \mathrm{~s}$ binding energies (Figure $3 \mathrm{~b}$ ) and will also be discussed in greater detail below.

3.3. Desorption of Molecular Glycine. The surface chemistry and stability of glycine was investigated using TPD. In previous investigations, $30 \mathrm{amu}\left(\mathrm{H}_{2} \mathrm{~N}-\mathrm{CH}_{2}{ }^{+}\right)$was selected to represent molecular desorption ${ }^{17,18}$ since this is an intense fragment mass of glycine. ${ }^{23}$ In cases where glycine does not decompose, $30 \mathrm{amu}$ is the best choice to monitor molecular desorption. 

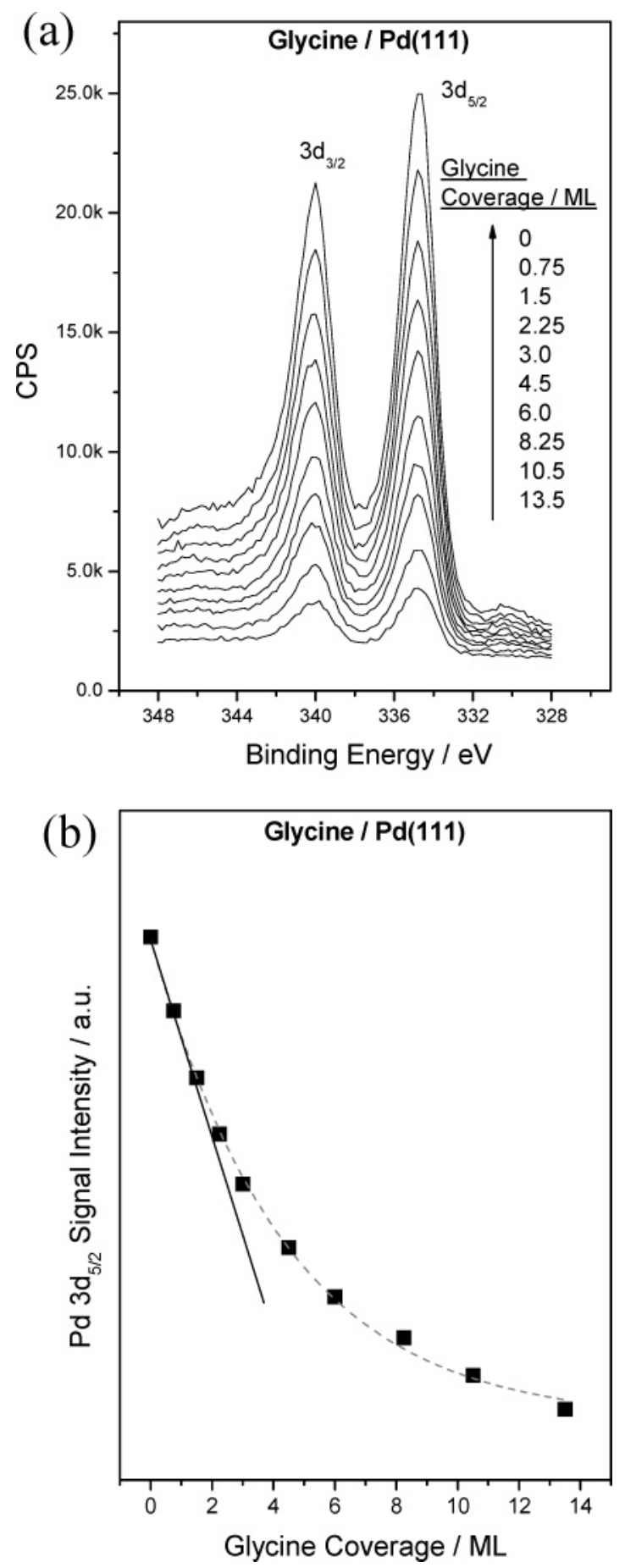

Figure 2. (a) Pd $3 \mathrm{~d}$ photoelectron spectra as a function of glycine coverage and (b) a plot of integrated $\mathrm{Pd} 3 \mathrm{~d}_{5 / 2}$ signal intensity vs glycine coverage.

However, as will be shown below, some glycine decomposition products contain fragments at $30 \mathrm{amu}$ so that $75 \mathrm{amu}$ (the parent mass of glycine) is chosen here to follow molecular desorption, despite its much lower signal intensity compared to that at $30 \mathrm{amu}$. Figure 5a presents the desorption of molecular glycine as a function of coverage. At a glycine coverage of $1.5 \mathrm{ML}$, a small amount of glycine desorbs at $336 \mathrm{~K}$. As the coverage increases, more glycine desorbs from the surface and the desorption temperature also increases so that, at $13.5 \mathrm{ML}$, it is centered at $363 \mathrm{~K}$. At coverages below 1.5 ML, it is not possible to detect molecular desorption at $75 \mathrm{amu}$ because of its low mass spectrometer sensitivity. However, as will be shown below, by comparing desorption temperatures and line shape changes

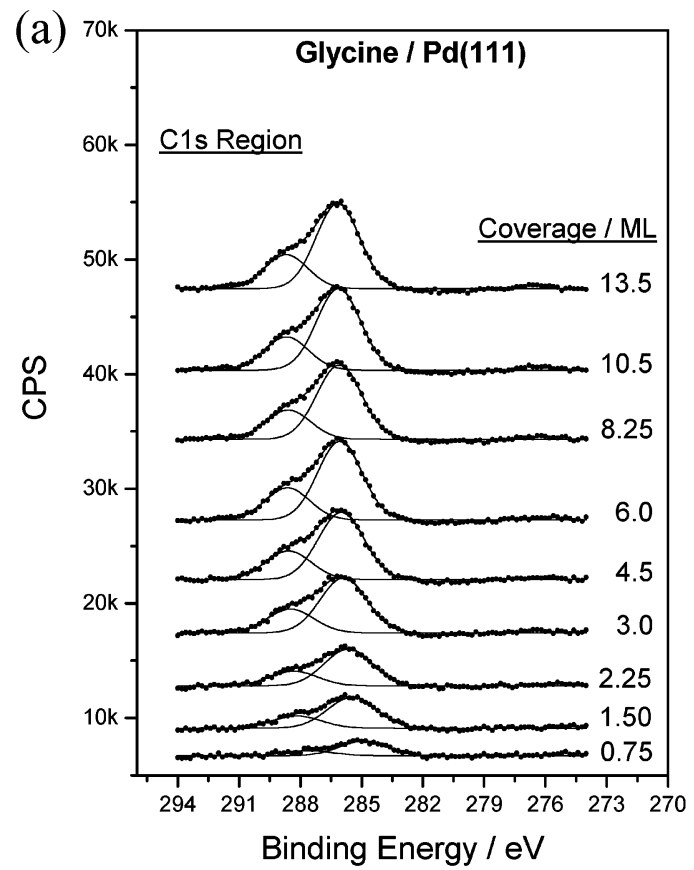

(b)

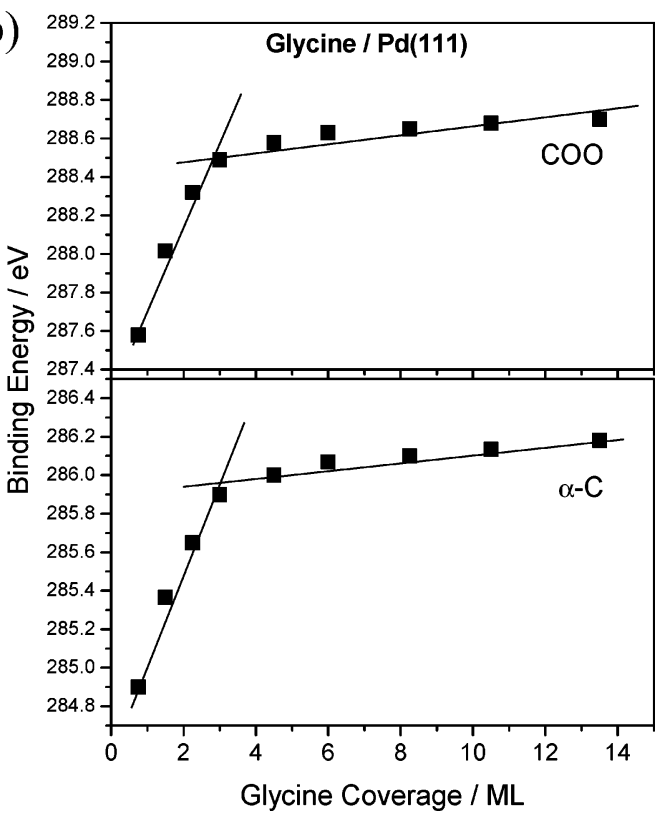

Figure 3. (a) $\mathrm{C} 1 \mathrm{~s}$ photoelectron spectra as a function of glycine coverage and (b) a plot of the binding energy of the $\mathrm{C} 1 \mathrm{~s}$ feature assigned to $\mathrm{COO}$ and $\alpha-\mathrm{C}$ vs glycine coverage.

at other masses, it is found that even at a coverage of $0.45 \mathrm{ML}$, some molecular desorption does occur.

The removal of carbon from the surface was also monitored using XPS by adsorbing 10.5 ML of glycine onto a Pd(111) surface and then annealing to higher temperatures. Figure $5 \mathrm{~b}$ displays the Pd $3 \mathrm{~d}$ spectral region as a function of annealing temperature and Figure $5 \mathrm{c}$ plots the corresponding $\mathrm{Pd} 3 \mathrm{~d}_{5 / 2}$ signal intensity versus annealing temperature. The slow Pd signal intensity increase below $300 \mathrm{~K}$ is likely due to some lowtemperature dissociation of glycine. However, the rapid signal increase between 300 and $380 \mathrm{~K}$ is clearly predominantly due to molecular glycine desorption (although also partially due to some glycine decomposition). This corresponds rather well with the TPD results shown in Figure 5a.

3.4. Decomposition of Adsorbed Glycine. Both XPS and TPD were used to monitor the decomposition of adsorbed 
(a)

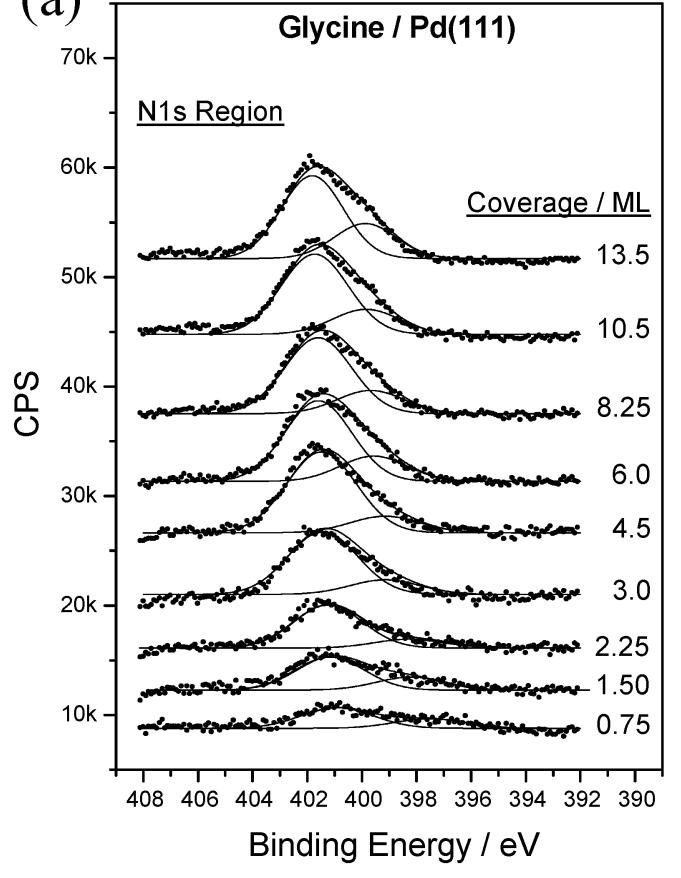

(b)

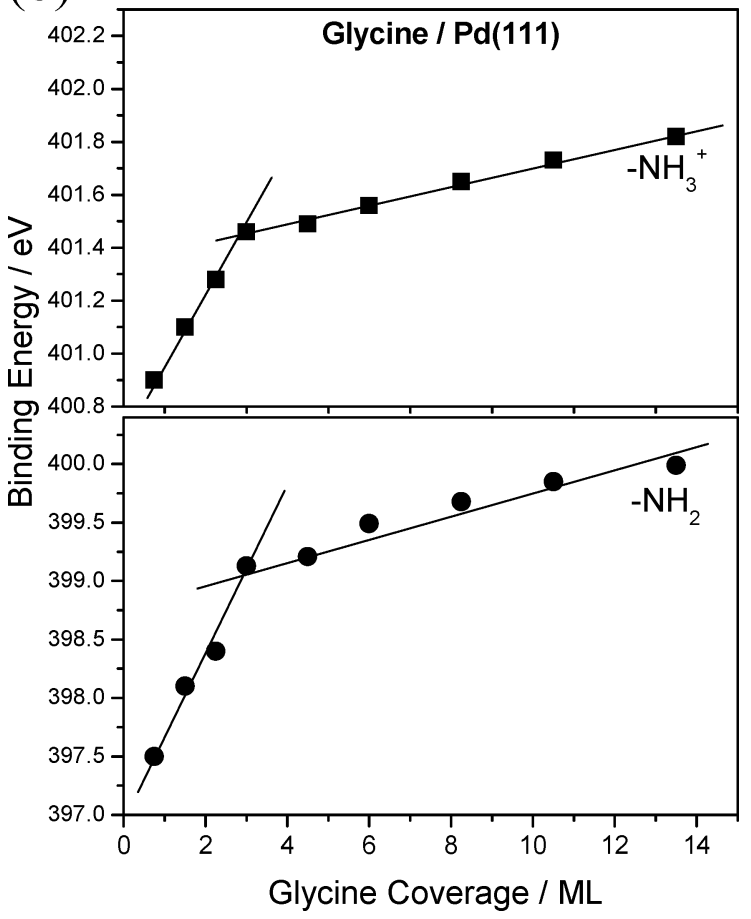

Figure 4. (a) $\mathrm{N} 1 \mathrm{~s}$ photoelectron spectra as a function of glycine coverage and (b) a plot of the binding energy of the $\mathrm{N} 1 \mathrm{~s}$ feature assigned to $-\mathrm{NH}_{3}{ }^{+}$and $-\mathrm{NH}_{2}$ vs glycine coverage.

glycine. Figure 6 depicts the XPS results for 3 ML of glycine on the $\operatorname{Pd}(111)$ surface after annealing to higher temperatures. It should be mentioned that during the annealing process, both molecular desorption (Figure 5a) and decomposition of glycine occurs. This makes the data analysis more complicated, but some useful information can still be obtained.

Figure 6a displays the $\mathrm{C} 1 \mathrm{~s}$ spectral region. These are fit to two features corresponding to the $\mathrm{COO}$ carbon at higher binding energies and the $\alpha-C$ at lower binding energies. Note that the lower binding energy region also includes carbon from dissociation products, especially at higher temperatures. Figure $6 \mathrm{~b}$ plots the corresponding $\mathrm{C} 1 \mathrm{~s}$ binding energies as a function of temperature. Below $\sim 290 \mathrm{~K}$, no binding shift or signal intensity decrease is observed, indicating the majority of adsorbed glycine remains intact over this temperature range. A clear signal intensity decrease is found on heating to $\sim 320 \mathrm{~K}$, consistent with the fact that both molecular desorption and dissociation start at this temperature (see below). This also causes a rapid decrease in $\mathrm{C}$ 1s binding, the reverse of the process found during adsorption, shown in Figure 3. Further signal intensity and binding energy decreases occur at higher temperatures, due partially to the desorption of molecular glycine, but also due to its decomposition. Note that the $\mathrm{COO}$ signal intensity decreases much more rapidly than the $\alpha-C$ signal. From 370 to $410 \mathrm{~K}$, the $\mathrm{COO}$ signal is almost undetectable, while a relatively strong $\alpha-C$ signal still persists.

Figure $6 \mathrm{c}$ displays the corresponding N 1s XP spectra, and Figure $6 \mathrm{~d}$ plots the corresponding binding energies as a function of annealing temperature. As expected, similar trends are found as for the $\mathrm{C} 1 \mathrm{~s}$ region, where no shift in binding energy is observed below $\sim 290 \mathrm{~K}$, but both the signal intensity and binding energy decrease at higher temperatures. It is worth pointing out that zwitterionic glycine is still rather stable at $320 \mathrm{~K}$. Above this temperature, the $-\mathrm{NH}_{3}{ }^{+}$signal intensity decreases very rapidly, suggesting that zwitterionic glycine decomposes and/or converts to glycinate.

TPD experiments were performed to gain a more detailed picture of the reaction pathways of chemisorbed glycine. Figure 7 presents desorption profiles collected at 2, 28, 30, and $44 \mathrm{amu}$ over a wide glycine coverage range from 1.5 to 13.5 ML. The left panel displays desorption at $2 \mathrm{amu}\left(\mathrm{H}_{2}\right)$. At low glycine coverages, hydrogen desorbs in three states at 370,420 , and $540 \mathrm{~K}$, where the $370 \mathrm{~K}$ state is more pronounced than the other two. At higher coverages, the $420 \mathrm{~K}$ state becomes undetectable, presumably obscured by the other two states and, in the meantime, the $540 \mathrm{~K}$ state becomes dominant. The spectra at the other three masses, by comparison with the molecular desorption profiles shown in Figure 5a, reveal immediately that these include fragments due to molecular glycine between 330 and $370 \mathrm{~K}$. Nevertheless, the 28 amu profiles reveal some CO desorption between 470 and $450 \mathrm{~K}$ depending on glycine coverage; the $30 \mathrm{amu}$ signals display a low-temperature shoulder centered at $\sim 300 \mathrm{~K}$, and the $44 \mathrm{amu}$ profiles indicate $\mathrm{CO}_{2}$ desorption at $\sim 385 \mathrm{~K}$.

Additional TPD experiments were preformed for a wider range of masses and lower glycine coverages (up to 0.81 ML to decrease overlap with molecular desorption and decomposition products) to gain more information on the reaction pathways. Figure 8 shows desorption at 29, 30, and 31 amu as a function of glycine coverage. Note first that glycine has no mass spectrometer ionizer fragment at $31 \mathrm{amu}^{23}$ so that desorption at 31 amu must derive exclusively from decomposition product(s). The relative signal intensities at these three masses match perfectly with the fragmentation pattern of methylamine $\left(\mathrm{CH}_{3} \mathrm{NH}_{2}\right)$. This clearly demonstrates that methylamine is formed from the dissociation of glycine between 330 and $315 \mathrm{~K}$ and that the reaction is slightly coverage dependent. Note also that, at glycine coverages of $0.45 \mathrm{ML}$ and greater, although the 31 amu desorption profiles are still relatively symmetric, the 29 and 30 amu signals start to skew to higher temperatures. At a coverage of $0.81 \mathrm{ML}$, a clear desorption state is found at $335 \mathrm{~K}$, which is assigned to the desorption of molecular glycine. This indicates that molecular desorption occurs at coverages as low as $\sim 0.45$ ML.

The corresponding desorption profiles at 26, 27, and $28 \mathrm{amu}$ are displayed in Figure 9 for low glycine coverages using a 

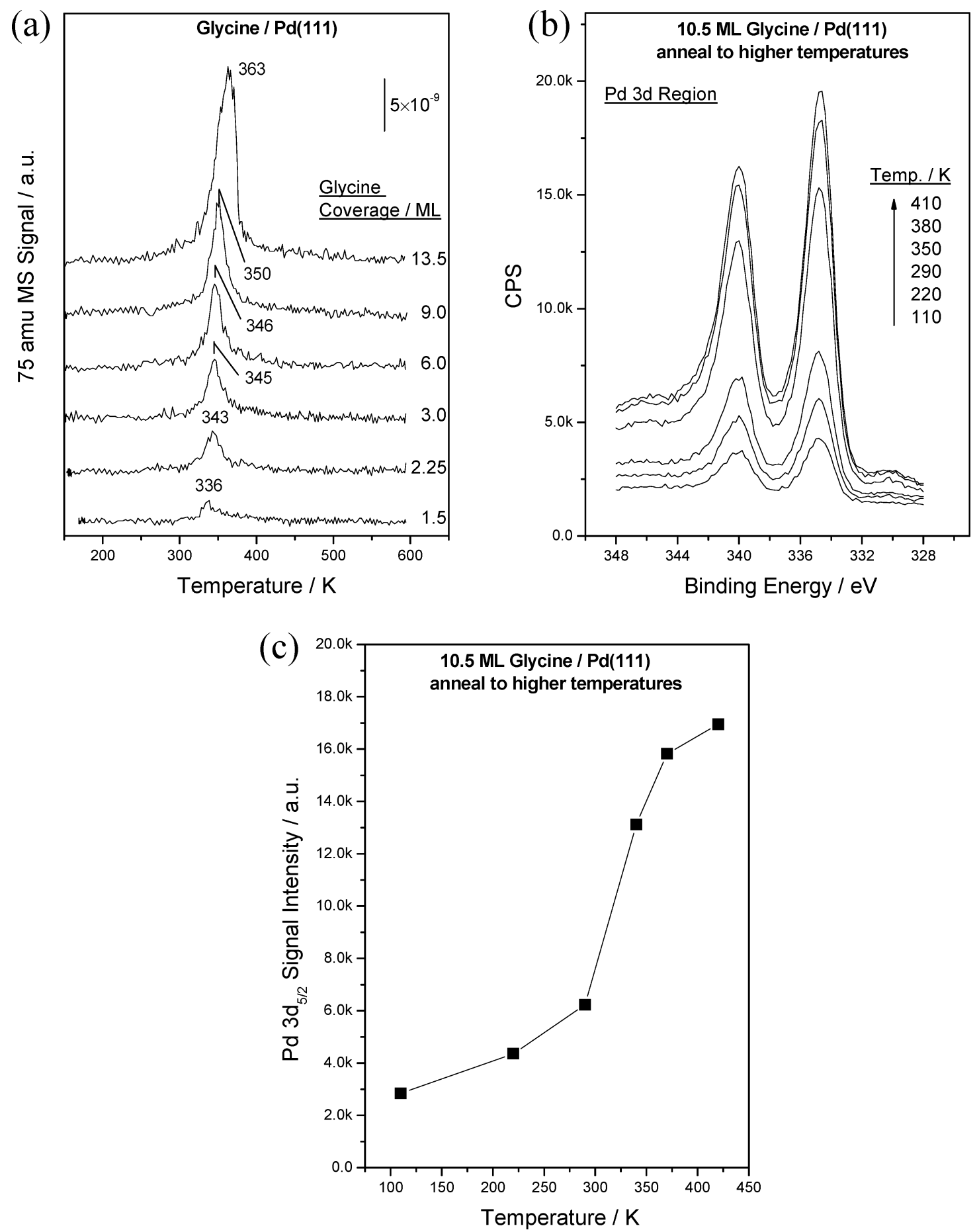

Figure 5. (a) Glycine ( $75 \mathrm{amu}$ ) desorption profiles as a function of glycine exposure collected at a heating rate of $6.5 \mathrm{~K} / \mathrm{s}$, (b) Pd $3 \mathrm{~d}$ photoelectron spectra for $3 \mathrm{ML}$ of glycine on $\mathrm{Pd}(111)$ as a function of annealing temperature, where the annealing temperatures are displayed adjacent to the corresponding spectrum, and (c) a plot of integrated $\mathrm{Pd} 3 \mathrm{~d}_{5 / 2}$ signal intensity vs annealing temperature.

higher heating rate of $10.5 \mathrm{~K} / \mathrm{s}$ to attain a final sample temperature of $850 \mathrm{~K}$. The line shapes at 26 and 27 amu are almost identical to each other but are markedly different from those at 28 amu. It should be mentioned that 24 and 25 amu signals were also monitored, but no detectable intensity was found (data not shown). From these data, the low-temperature desorption state (centered at $\sim 345 \mathrm{~K}$ at a coverage of $0.81 \mathrm{ML}$ ) is assigned to fragmentation of molecular methylamine and/or glycine. The $\sim 10 \mathrm{~K}$ difference in peak temperature compared with data shown in Figure 8 (taken at a heating rate of $6.5 \mathrm{~K} / \mathrm{s}$ ) is due to the higher heating rate. Three high-temperature states are found for 26 and $27 \mathrm{amu}$, at 430, 535, and $740 \mathrm{~K}$. The
$535 \mathrm{~K}$ state only becomes pronounced at a coverage of $0.81 \mathrm{ML}$. Since these features are found only at 26 and $27 \mathrm{amu}$ and not at any other masses, these are assigned to $\mathrm{HCN}$ desorption. The relative intensities at 26 and 27 amu correspond well with the published mass spectrometer ionizer fragmentation pattern of $\mathrm{HCN} .{ }^{23}$ The $503-480 \mathrm{~K}$ desorption state at $28 \mathrm{amu}$ is evidently due to $\mathrm{CO}$ desorption.

Desorption at between 41 and 45 amu was also monitored (Figure 10). Desorption at 42 amu can be safely assigned to the fragmentation of molecular glycine since the desorption temperature is very close to that shown in Figure 8. However, desorption at other masses clearly points to dissociation products 
(a)

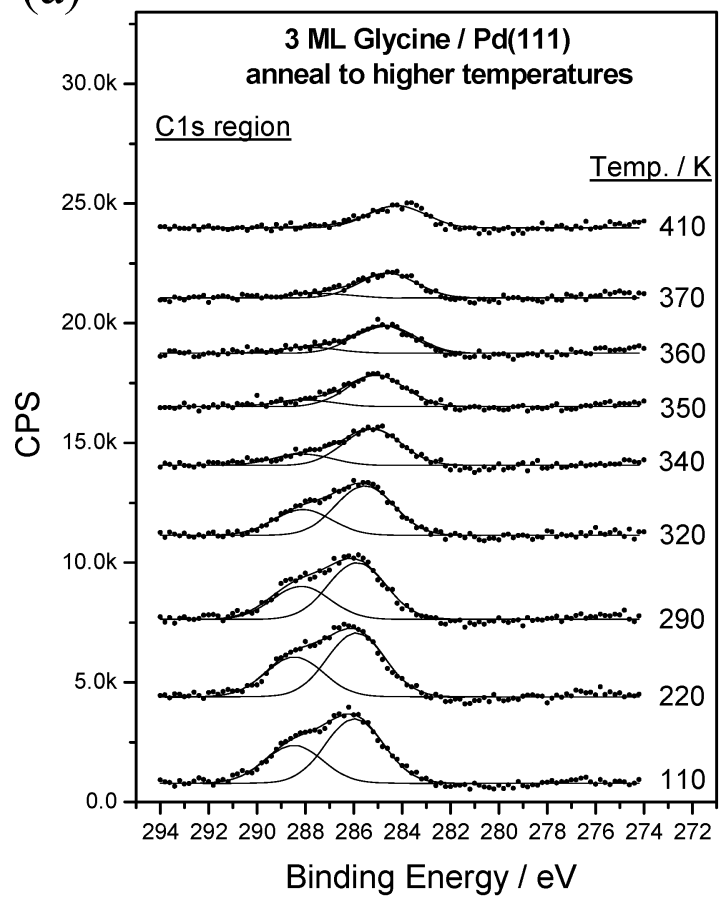

(c)

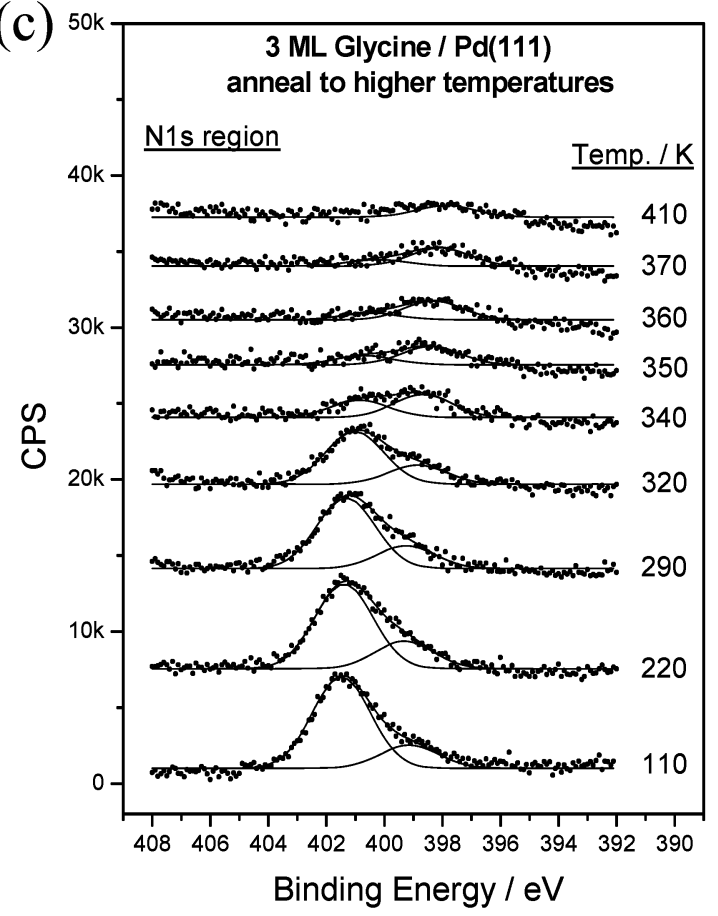

(b)

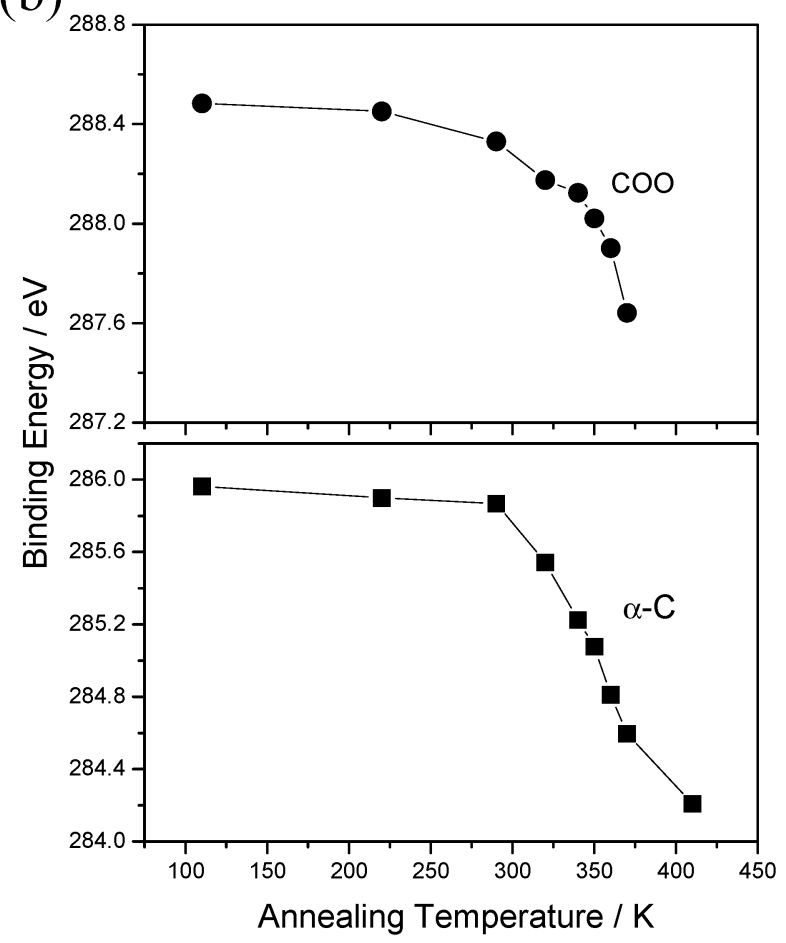

(d)

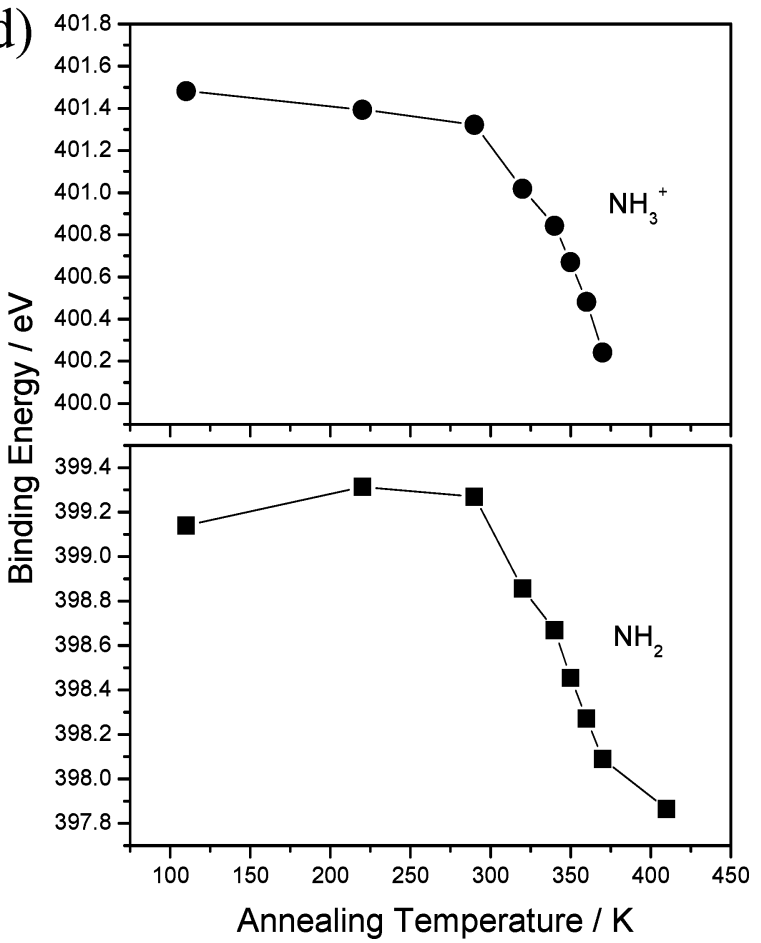

Figure 6. (a) $\mathrm{C}$ 1s photoelectron spectra for $3 \mathrm{ML}$ of glycine on $\mathrm{Pd}(111)$ as a function of annealing temperature, where the annealing temperatures are displayed adjacent to the corresponding spectrum, (b) a plot of the binding energies of the $\mathrm{C} 1 \mathrm{~s}$ feature assigned to $\mathrm{COO}$ and $\alpha$-C vs temperature, (c) $\mathrm{N}$ 1s photoelectron spectra as a function of glycine coverage, and (d) a plot of the binding energies of the $\mathrm{N}_{1} 1 \mathrm{~s}$ feature assigned to $-\mathrm{NH}_{3}{ }^{+}$and $-\mathrm{NH}_{2}$ vs annealing temperature.

since the desorption temperatures are higher than that of molecular glycine. The only possible candidates for these masses are formic acid, acetic acid, and $\mathrm{CO}_{2}$. Desorption at $44 \mathrm{amu}$ is due predominately to $\mathrm{CO}_{2}$, since both formic acid and acetic acid display very weak fragments at 44 amu. Unfortunately, because the 44 amu signals are relatively intense, there is some cross-contamination of the 43 and 45 amu signals (note the line shape similarities among the 43-45 amu signals), making an unambiguous assignment of the acidic product difficult. We tentatively assign the desorption at 41,43 , and 45 amu to acetic acid because formic acid does not have a 41 amu fragment.

Finally, 12, 14, 16, 17, and 18 amu spectra were monitored to investigate the formation of water and ammonia (Figure 11). At very low glycine coverages (from 0.09 to $0.18 \mathrm{ML}$ ), a sharp desorption feature was found at 17 and 18 amu centered at $\sim 300 \mathrm{~K}$, due to water desorption. At higher glycine coverages, 


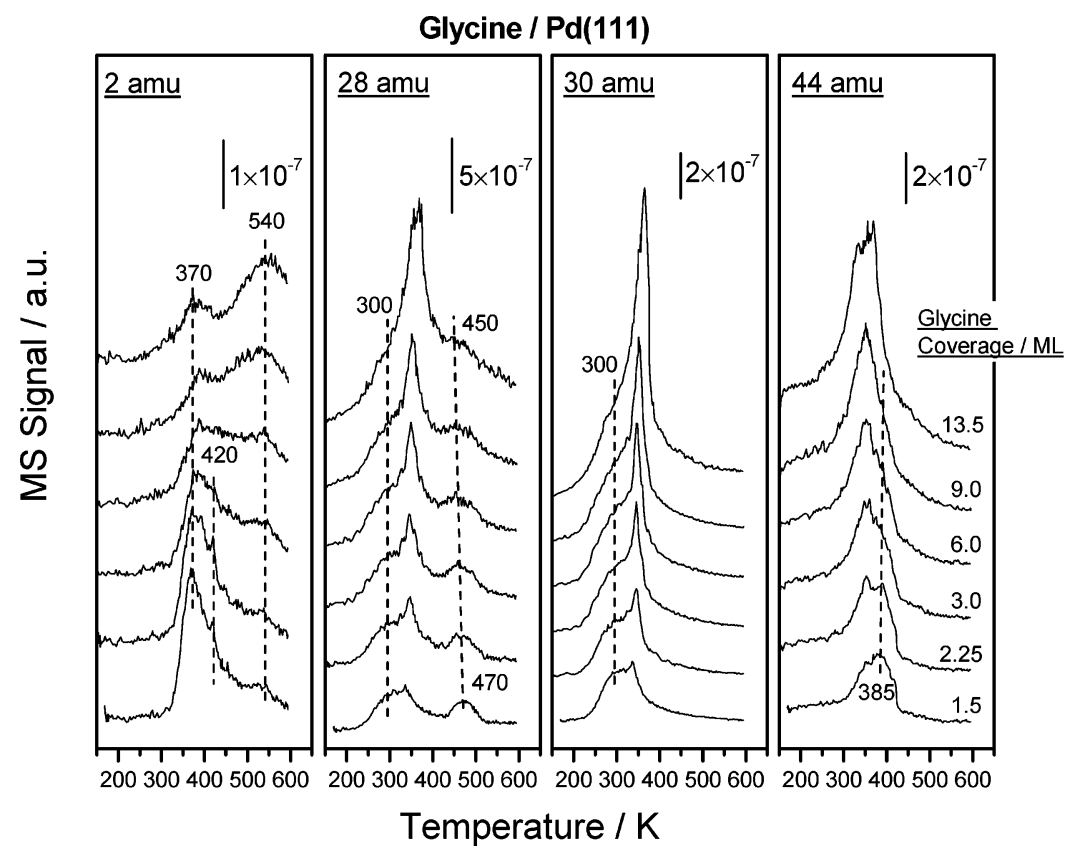

Figure 7. Graphs of 2, 28, 30, and 44 amu TPD profiles for various coverages of glycine on $\mathrm{Pd}(111)$ collected using a heating rate of $6.5 \mathrm{~K} / \mathrm{s}$, where the glycine coverages are displayed adjacent to the corresponding spectrum.

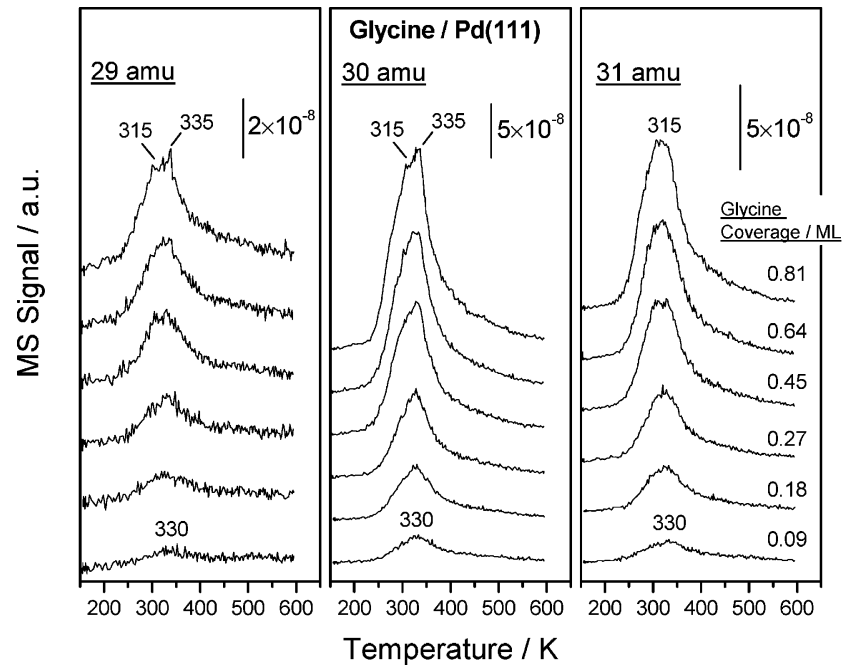

Figure 8. Graphs of 29,30 , and $31 \mathrm{amu}$ TPD profiles for various coverages of glycine on $\mathrm{Pd}(111)$ collected using a heating rate of $6.5 \mathrm{~K} / \mathrm{s}$, where the glycine coverages are displayed adjacent to the corresponding spectrum.

the line shapes of the 17 and 18 amu profiles become somewhat different, where water desorption (18 amu) appears at $\sim 360 \mathrm{~K}$. The difference between the 17 and 18 amu profiles suggests that the $17 \mathrm{amu}$ signals contain contributions from other desorption products. However, by monitoring desorption at 14 and 16 amu, no strong indication for the formation of ammonia was found. First, the line shapes and desorption temperatures at 14 amu resemble those at 31 amu (due to methylamine, Figure 8). Second, desorption of ammonia would yield a fragment at 16 amu. However, the 16 amu signals resemble those at 44 amu indicating that these are due mainly to fragmentation of $\mathrm{CO}_{2}$. Therefore, it is concluded that the formation of ammonia, even if exists, must be very minor. The 12 amu desorption profile was also monitored, and it was found that this is due to fragmentation of $\mathrm{CO}_{2}($ at $380 \mathrm{~K}$ ) and $\mathrm{CO}$ (at $480 \mathrm{~K})$.

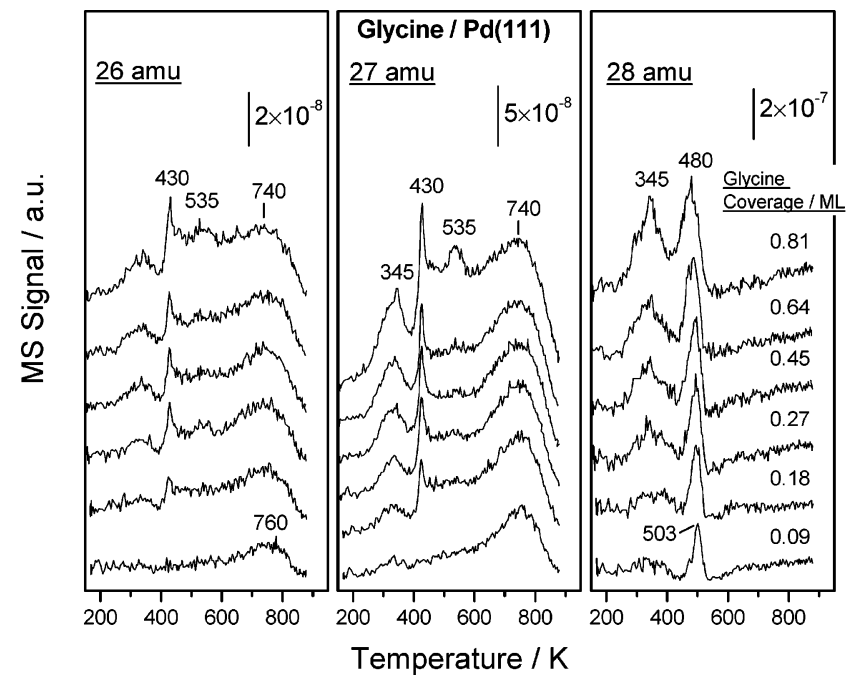

Figure 9. Graphs of 26, 27, and 28 amu TPD profiles for various coverages of glycine on $\mathrm{Pd}(111)$ collected using a heating rate of $10.5 \mathrm{~K} / \mathrm{s}$, where the glycine coverages are displayed adjacent to the corresponding spectrum.

\section{Discussion}

4.1. Coverage of Glycine on $\operatorname{Pd}(\mathbf{1 1 1})$. The data of Figures 3 and 4 reveal that the amount of carbon and nitrogen on the surface increases continually with increasing glycine dose implying that adsorption on the surface is not limited at a monolayer but grows continually. This notion is corroborated by the data of Figure 2, which show a substantial decrease in the substrate palladium signals with exposure indicative of the formation of relatively thick and uniform glycine films, and is consistent with the TPD data (Figure 7) showing hightemperature desorption of glycine above $300 \mathrm{~K}$ for rather thick films. Similar effects have been noted for glycine adsorption on $\operatorname{Pt}(111)$, where, in this case, desorption from second and subsequent layers can be resolved in TPD. ${ }^{17}$ Finally, it is consistent with the relatively high temperatures required to sublime solid amino acids (Figure $1^{24}$ ). This indicates that 


\section{Glycine / Pd(111)}

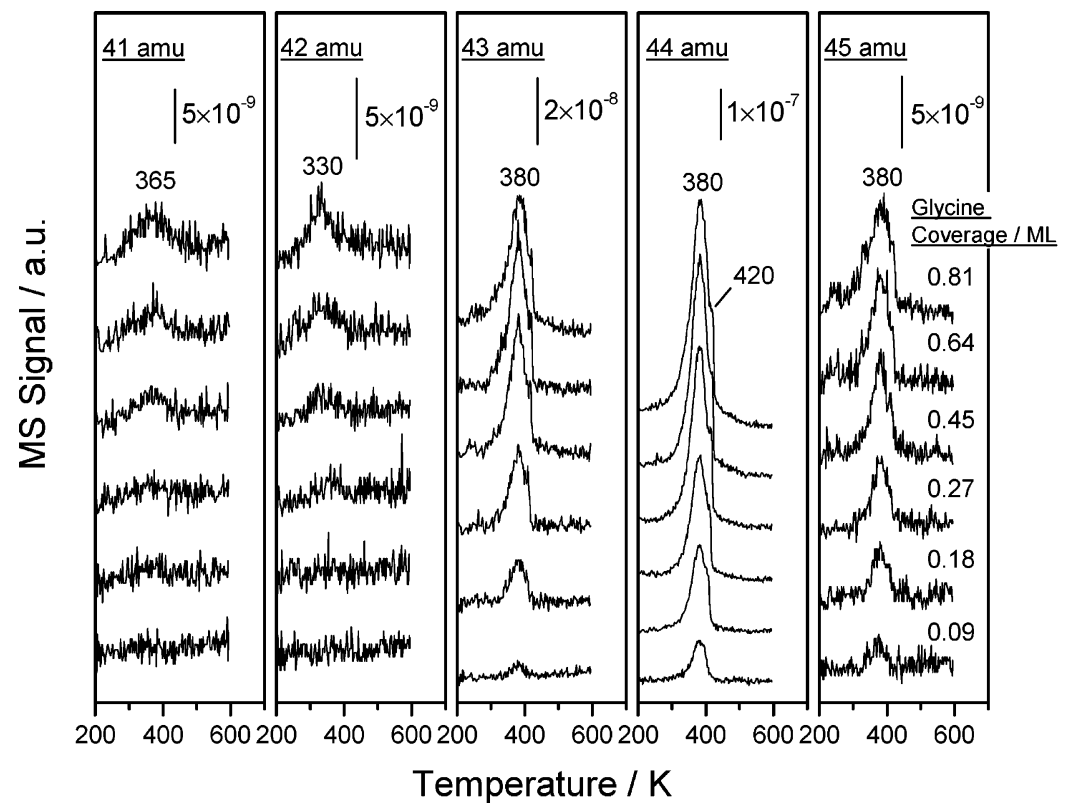

Figure 10. Graphs of $41,41,43,44$, and 45 amu TPD profiles for various coverages of glycine on $\operatorname{Pd}(111)$ collected using a heating rate of $6.5 \mathrm{~K} / \mathrm{s}$, where the glycine coverages are displayed adjacent to the corresponding spectrum.

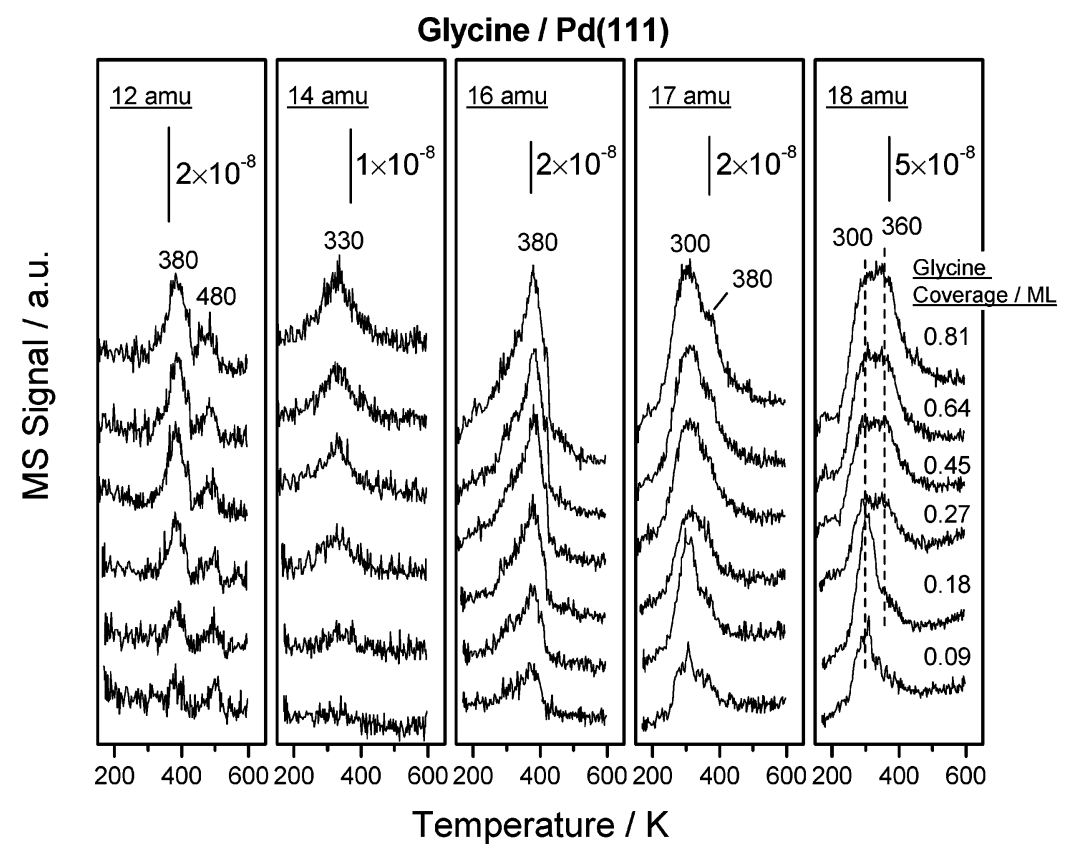

Figure 11. Graphs of 12,14, 16, 17, and 18 amu TPD profiles for various coverages of glycine on Pd(111) collected using a heating rate of 6.5 $\mathrm{K} / \mathrm{s}$, where the glycine coverages are displayed adjacent to the corresponding spectrum.

glycine not only adsorbs strongly to the bare $\operatorname{Pd}(111)$ surface but also into second and subsequent layers. Thus, the rate of absorption onto the surface depends on the flux $F$ (in $\mathrm{ML} / \mathrm{min}$ ) from the dosing source and the sticking coefficient $S$. If the glycine coverage on the bare surface is given by $\Theta_{0}$, and into the first layer by $\Theta_{1}$, into the second layer by $\Theta_{2}$, and into the $n$th layer by $\Theta_{n}$, then, assuming that $S$ is identical for all layers yields the total coverage $\Theta_{\text {tot }}$ :

$$
\Theta_{\mathrm{tot}}=\sum_{1}^{\infty} \Theta_{1}=F S t
$$

where $t$ is the dosing time. The rate of change of coverage in each layer is give by

$$
\begin{aligned}
& \frac{\mathrm{d} \Theta_{1}}{\mathrm{~d} t}=F S \Theta_{0}, \quad \frac{\mathrm{d} \Theta_{2}}{\mathrm{~d} t}=F S\left(\Theta_{1}-\Theta_{2}\right), \\
& \quad \frac{\mathrm{d} \Theta_{3}}{\mathrm{~d} t}=F S\left(\Theta_{2}-\Theta_{3}\right), \quad \ldots \quad \frac{\mathrm{d} \Theta_{n}}{\mathrm{~d} t}=F S\left(\Theta_{n-1}-\Theta_{n}\right),
\end{aligned}
$$

and, since these refer to the relative coverage in each layer, $\Theta_{0}$ $+\Theta_{1}=1$. These equations can be solved analytically to yield

$$
\begin{gathered}
\Theta_{0}=\exp (-F S t), \quad \Theta_{1}=1-\exp (-F S t) \\
\Theta_{2}=1-(1+F S t) \exp (-F S t) \text { and } \\
\Theta_{3+}=2(\exp (-F S t)-1)+F S t(1+\exp (-F S t))
\end{gathered}
$$

where $\Theta_{3+}$ is the total coverage in the third and subsequent 


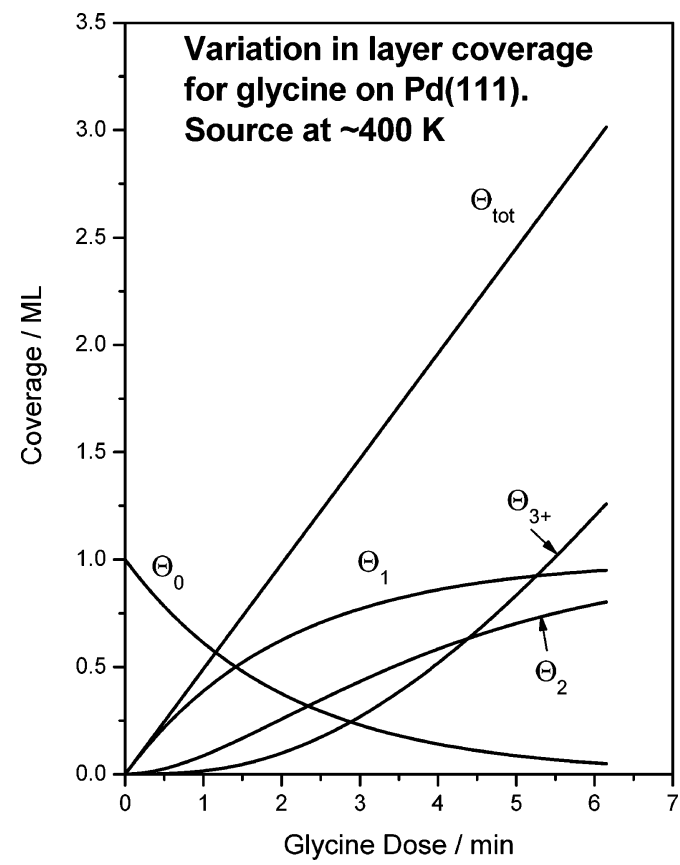

Figure 12. Calculated glycine coverages in the first $\left(\Theta_{1}\right)$, second $\left(\Theta_{2}\right)$, and third and subsequent $\left(\Theta_{3+}\right)$ layers as a function of glycine dose for a source temperature of $400 \mathrm{~K}$ plotted using the parameters taken from analysis of the data in Figure 1b (see text).

layers. Thus, the decrease in ${ }^{13} \mathrm{CO}$ yield as a function of glycine dose depicted in Figure 1 is due to a decrease in the proportion of the surface that remains uncovered by glycine $\left(\Theta_{0}\right)$. Shown on these data are exponential fits (see eq 2 ) which yield values of $F S=0.49 \pm 0.02 \mathrm{ML} / \mathrm{min}$ for a source temperature of $\sim 400 \mathrm{~K}$ and $0.050 \pm 0.005 \mathrm{ML} / \mathrm{min}$ at a source temperature of $\sim 360 \mathrm{~K}$. The total coverage can then be calculated from eq 1 , and all data are labeled with the total glycine coverage measured in this way. The coverage in each layer can also be calculated from eq 3 , and the results, for a dosing source temperature of $\sim 400 \mathrm{~K}$, are plotted in Figure 12 as a function of glycine dose. This shows that the coverage of glycine in the second layer is significant by the time that the first layer has saturated and that the total glycine coverage is about three monolayers when the first layer has saturated.

4.2. Molecular Adsorption of Glycine. The binding energies of $\mathrm{C} 1 \mathrm{~s}$ and $\mathrm{N} 1 \mathrm{~s}$ features shown in Figures 3 and 4 indicate that glycine adsorbs molecularly at $\sim 100 \mathrm{~K}$ and the majority of adsorbed glycine remains intact until at least at $290 \mathrm{~K}$ (Figure 6, parts a and c). Solid glycine occurs in its zwitterionic form $\left(\mathrm{NH}_{3}{ }^{+}-\mathrm{CH}_{2}-\mathrm{COO}^{-}\right)$. Glycine adsorbed as zwitterions in the monolayer regime has been found previously on $\mathrm{Au},{ }^{11,12}$ $\mathrm{Ag},{ }^{14} \mathrm{Pt},{ }^{25}$ and $\mathrm{NiAl},{ }^{18}$ and $\mathrm{AuCu}$ alloys. ${ }^{20}$ The data shown in Figure $4 \mathrm{a}$ indicate that $\sim 80 \%$ of the glycine adsorbs in the zwitterionic form at low coverages, decreasing slightly to $\sim 70 \%$ at higher coverages. The $\mathrm{C} 1 \mathrm{~s}$ and N1s chemical shifts vary with coverage, showing a rapid change with coverage up to $\sim 3 \mathrm{ML}$ and a slower variation at higher coverages. Such a variation of chemical shift with coverage has been noted previously for glycine on $\operatorname{Pt}(111),{ }^{17}$ and the abrupt change at a total coverage of $\sim 3$ ML coincides with the saturation of the first layer (Figure 12). The slow variation in binding energy at coverages $>3 \mathrm{ML}$ has been previously assigned to a charging shift due to the formation of a thick glycine layer. The binding energy shift at lower coverages can be partly ascribed to this effect. However, the most likely origin of the larger shift in binding energy below a total glycine coverage of $\sim 3 \mathrm{ML}$ is the simultaneous presence of several glycine-derived species on the
TABLE 1: Binding Energies, in eV, for Glycine Adsorbed on $\operatorname{Pt}(111)$ (Ref 17) and on Pd(111) (This Work) ${ }^{a}$

\begin{tabular}{lcccc}
\hline & $\mathrm{C} 1 \mathrm{~s} \mathrm{COO}$ & $\mathrm{C} 1 \mathrm{~s} \alpha-\mathrm{C}$ & $\mathrm{N} \mathrm{1s} \mathrm{\textrm {NH } _ { 2 }}{ }^{-}$ & ${\mathrm{N} 1 \mathrm{~s} \mathrm{NH}_{3}}^{+}$ \\
\hline $\mathrm{Pd}(111)$ monolayer & 287.3 & 284.6 & 397.0 & 400.7 \\
$\mathrm{Pt}(111)$ monolayer & 289.18 & 284.4 & 399.9 & 401.28 \\
$\mathrm{Pd}(111)$ multilayer & 288.5 & 285.9 & 398.8 & 401.4 \\
$\mathrm{Pt}(111)$ multilayer & 289.42 & 285.7 & 400.53 & 402.48
\end{tabular}

${ }^{a}$ The monolayer values are estimated by extrapolating the binding energy data for coverages below $\sim 3 \mathrm{~L}$ to zero coverage, whereas the multilayer data are found by extrapolating the data collected for coverages above 3 ML to zero coverage to compensate for charging effects.

surface, with a coverage variation shown in Figure 12. Thus, extrapolating the data in Figures $3 b$ and $4 b$ to zero coverage should yield values close to the chemical shifts for glycine adsorbed directly to $\mathrm{Pd}(111)$, yielding $\mathrm{C} 1 \mathrm{~s}$ binding energies of $\sim 287.3$ and $\sim 284.6 \mathrm{eV}$ and $\mathrm{N} 1$ s binding energies of $\sim 397.0$ and $\sim 400.7 \mathrm{eV}$. It should be noted that this extrapolation assumes that the intensities of these features are not zero in the monolayer. The binding energies for glycine on $\operatorname{Pd}(111)$ are compared with data collected for $\operatorname{Pt}(111)^{17}$ in Table 1. Acetate species are formed following acetic acid adsorption on $\operatorname{Pd}(111)$ and exhibit $\mathrm{C} 1 \mathrm{~s}$ features at $\sim 288.5 \mathrm{eV}$ due to the carboxylate and at $284.9 \mathrm{eV}$ due to the methyl group. ${ }^{26}$ The $\mathrm{C} 1 \mathrm{~s}$ binding energies of the $\alpha-\mathrm{C}$ and the methyl group are in good agreement, whereas the $\mathrm{COO}$ binding energy of the amino acid is shifted by $\sim 1 \mathrm{eV}$ compared to that for the acetate species. As noted above, the data of Figure 4 indicate that adsorbed glycine is present in two forms, both zwitterionic and neutral. In addition, the $\mathrm{N}$ 1s binding energies on $\mathrm{Pd}(111)$ differ from those on Pt(111). This may connote different interactions between the nitrogen and the surface for $\mathrm{Pd}(111)$ and $\mathrm{Pt}(111)$ or, alternatively, different adsorption geometries. Further evidence for different adsorption geometries comes from the relative intensities of the $\mathrm{C} 1 \mathrm{~s}$ features in Figure 5, where the $\mathrm{C} 1 \mathrm{~s}$ feature, due to the $\alpha-C$, is consistently more intense than that due to $\mathrm{COO}$, whereas on $\operatorname{Pt}(111)$ these have approximately equal intensities. ${ }^{17}$ It is possible that the geometry of adsorption into second and subsequent layers is controlled by the adsorption geometry in the first layer, and the more intense $\alpha-C$ feature may suggest that the $\mathrm{C}-\mathrm{C}$ bond is oriented more closely to perpendicular to the surface on $\operatorname{Pd}(111)$ than on $\operatorname{Pt}(111)$.

The remainder of the glycine should therefore be present in the neutral form $\left(\mathrm{NH}_{2}-\mathrm{CH}_{2}-\mathrm{COOH}\right)$. Previous investigations have shown that small carboxylic acids, for example acetic acid, remain intact on $\mathrm{Pd}(111)$ at $\sim 80 \mathrm{~K} .{ }^{26}$ Replacing one $\mathrm{H}$ atom on the $\alpha-\mathrm{C}$ with an amino group should not cause the $-\mathrm{OH}$ bond to cleave more easily since it is an electron donor. Also note that, in the multilayer, only $70 \%$ of glycine is present as zwitterions. The remainder must be neutral to maintain the original molecular stoichiometry. It should be emphasized that this argument only applies at low temperatures. At temperatures where the adsorbate starts to dehydrogenate, no matter in what form it eventually appears $\left(\mathrm{H}_{2}, \mathrm{H}_{2} \mathrm{O}\right.$, etc.), glycinate must be generated. It could be argued that the $\mathrm{N} 1 \mathrm{~s}$ signal detected at 397.5-400 eV, assigned to neutral glycine, may be due to nitrogen-containing contaminants. However, although this cannot be completely excluded, it is unlikely that this comprises $20 \%$ of the total nitrogen signal. We performed additional XPS measurements at a dosing source temperature of $350 \mathrm{~K}$, where the extent of glycine dissociation within the dosing source will be much less than at $400 \mathrm{~K}$. A N 1s signal at 397.5-400 eV can still be readily detected that also comprises $20 \%$ of the total nitrogen signal, strongly suggesting that this feature is not due 
to contaminants or decomposition products. Moreover, Lofgren et al. ${ }^{17}$ have demonstrated that, even at a dosing source temperature of $409 \mathrm{~K}$, glycine dissociation induced contamination is still very limited.

In principle, two mechanisms are possible for the conversion from the neutral form in the gas phase to a zwitterion on the surface. First, the neutral glycine molecule could react with the surface, leading to $-\mathrm{OH}$ bond cleavage to generate $\mathrm{O}-\mathrm{M}$ bonds and adsorbed hydrogen. Following that, hydrogen could transfer to the $-\mathrm{NH}_{2}$ group to form $-\mathrm{NH}_{3}{ }^{+}$. This process involves only adsorbate-substrate interactions and requires the metallic substrate to "hold" hydrogen long enough to allow the transfer. It is possible, in this case, that adsorbed hydrogen could recombine to desorb as $\mathrm{H}_{2}$, trapping glycinate species (the anionic form) on the surface. An alternative possibility is that adjacent glycine molecules interact with one another to form zwitterions directly since this is energetically favored in the solid phase. The occurrence of this process has been proven previously by coadsorption of normal and perdeuterated amino acids on the surface ${ }^{27}$ and does not necessarily require the participation of the substrate. The incompleteness of this process results in neutral amino acid on the surface. The final form of glycine (as well as other $\alpha$-amino acids) on the surface within the submonolayer regime will therefore depend delicately on the rate and extent of the above-mentioned reactions, which are controlled mainly by the nature of the metallic substrate and temperature. For gold surfaces, $\mathrm{O}-\mathrm{H}$ bond scission does not occur. However, glycine adsorbs exclusively in the zwitterionic form, presumably caused by direct hydrogen transfer between adsorbed glycine molecules. ${ }^{11,12}$ In the case of copper substrates ${ }^{9}$ at ambient temperatures, the interaction between the surface and glycine is rather strong so that $-\mathrm{OH}$ cleavage occurs. However, hydrogen does not remain in the copper surface to allow transfer to the amino group forming exclusively glycinate. $\mathrm{Pt}(111)$ reacts reasonably strongly with glycine, and hydrogen adsorbs relatively strongly, so that glycine adsorbs predominately in its zwitterionic form on $\mathrm{Pt}(111) .{ }^{17}$ Our results indicate that Pd(111) displays similar behavior. On $\mathrm{NiAl}(110)$, glycine is present in its zwitterionic form at $120 \mathrm{~K}$ but the anionic form at $310 \mathrm{~K} .^{18}$ This is consistent with the fact that hydrogen adsorbs on the surface at low temperatures but desorbs at room temperature. These results taken together indicate that hydrogen transfer to form zwitterions on transition metal surfaces is surface mediated and that the stable form is largely dictated by the stability of hydrogen on the surface.

The strong dependence of binding energy on glycine coverage is very interesting (Figures 3 and 4), and a similar phenomenon has been found on $\mathrm{Pt}(111) .{ }^{17}$ In the multilayer regime, the binding energy increase as a function of glycine coverage can be easily ascribed to charging effects. The higher binding energy of the multilayer regime with respect to the monolayer is also reasonably well understood. As suggested by Lofgren et al., ${ }^{17}$ this is due to both relaxation and chemical shifts. The chemical shift within the first layer is more difficult to explain. It depends on the detailed charge rearrangements among the valence orbitals around nitrogen and carbon atoms and thus requires detailed geometric information of adsorbed glycine molecules. To fully address this issue, more detailed structural measurements are required.

4.3. Glycine Decomposition on Pd(111). Two straightforward dissociation pathways for glycine are possible: $\mathrm{C}-\mathrm{C}$ bond and/or $\mathrm{C}-\mathrm{N}$ bond scission. The former forms methylamine and $\mathrm{CO}_{2}$, whereas the latter generates chemisorbed acetate and ammonia. As has been pointed out previously, the charge distribution of zwitterionic glycine weakens the $\mathrm{C}-\mathrm{C}$ bond thus facilitating cleavage. ${ }^{16}$ Our TPD and XPS results demonstrate that $\mathrm{C}-\mathrm{C}$ bond scission also dominates on $\mathrm{Pd}(111)$, and this conclusion is supported by the following observations: (1) the COO $\mathrm{C} 1 \mathrm{~s}$ signal disappears at lower temperatures than the $\alpha$-carbon $\mathrm{C} 1 \mathrm{~s}$ signal and (2) the desorption of methylamine (Figure 8) and $\mathrm{CO}_{2}$ are detected (Figure 10). The fact that there is no strong evidence for ammonia desorption (Figure 11), and the very weak acetic acid signal (Figure 10), indicates that $\mathrm{C}-\mathrm{N}$ bond cleavage is essentially nonexistent.

We first examine the nitrogen-containing desorption products. Figure 8 clearly demonstrates the formation of methylamine at slightly above room temperature. Not all nitrogen from glycine dissociation desorbs as methylamine as indicated by data shown in Figure 6c, where a $N$ 1s signal can still be detected at $410 \mathrm{~K}$. This is in complete agreement with the TPD results shown in Figure 9, where HCN desorption is found above 400 K. A systemic study by Chen and Winograd ${ }^{28}$ of the dissociation of methylamine on $\mathrm{Pd}(111)$ found that chemisorbed methylamine dehydrogenates to produce surface $\mathrm{CH}_{x} \mathrm{~N}_{(\text {ads })}(x \leq 3)$ species at temperatures above $275 \mathrm{~K}$. This process is complete between 320 and 360 to form $\mathrm{CN}_{(\mathrm{ads})}$. Finally, on the basis of deuterium-labeled TPD experiments, $\mathrm{CN}_{(\mathrm{ads})}$ recombines with $\mathrm{H}$ atoms that diffuse from the bulk to form $\mathrm{HCN}$ at temperatures above $390 \mathrm{~K}$. The data shown in Figure 9 clearly demonstrate that similar chemistry occurs in the present study and accounts for $\mathrm{HCN}$ desorption at $430 \mathrm{~K}$. However, this cannot explain $\mathrm{HCN}$ desorption at 535 and $740 \mathrm{~K}$. It is clear, however, for these two high-temperature states, that $\mathrm{HCN}$ formation must be reaction rate limited, presumably by the availability of surface hydrogen. This must derive from the decomposition of surface species since, at low glycine coverages, the majority of surface hydrogen desorbs molecularly below $500 \mathrm{~K}$ (Figure 7). Another possible difference between methylamine/Pd(111) and glycine/ $\mathrm{Pd}(111)$ that leads to high-temperature $\mathrm{HCN}$ formation in the latter case is surface oxygen, which does not exist in the former case but is present in the latter, where a portion of $\mathrm{COO}$ groups dissociate to form $\mathrm{CO}$ and deposit oxygen on the surface (Figures 7 and 9). It should be pointed out that the $\mathrm{CN}_{(\mathrm{ads})}$ precursor is not necessarily only methylamine and could well be $\mathrm{CH}_{x} \mathrm{~N}$ species formed directly from glycine decomposition.

We now turn our attention to oxygen-containing desorption products. Some water desorption is found centered at 300 and $360 \mathrm{~K}$ (Figure 11). Controlled experiment using $\mathrm{D}_{2} \mathrm{O}$ adsorption on a glycine-covered surface (data not shown) revealed that it desorbs below $200 \mathrm{~K}$ so that water formation, in this case, is surface reaction rate limited. This implies that a small proportion of the adsorbed glycine dissociates below $300 \mathrm{~K}$ to generate surface hydrogen and oxygen, even though the majority of the glycine remains intact until much higher temperatures.

The majority of the oxygen from glycine desorbs in the form of $\mathrm{CO}_{2}$ at $380 \mathrm{~K}$ (Figure 8). Since $\mathrm{CO}_{2}$ derives exclusively from surface carboxylate species, whether or not it is deprotonated, this suggests that the majority of $\mathrm{C}-\mathrm{C}$ bond cleavage in glycine occurs at this temperature. Note that a small amount of $\mathrm{C}-\mathrm{C}$ bond cleavage occurs at lower temperatures to generate methylamine. Haley et al. ${ }^{26}$ studied the dissociation of acetic acid on $\operatorname{Pd}(111)$ and found that, between 200 and $275 \mathrm{~K}, \mathrm{CO}_{2}$ formation is due to the dissociation of monodentate acetate, whereas $\mathrm{CO}_{2}$ desorption between 275 and $375 \mathrm{~K}$ is due to the dissociation of bidentate acetate. In the present study, the $\mathrm{CO}_{2}$ desorption temperature is somewhat higher, but reasonably close, to that of bidentate acetate. Of course this does not mean that $\mathrm{CO}_{2}$ formed in this study is due to $\mathrm{COO}$ dissociation, since the 
majority of $\mathrm{C}-\mathrm{N}$ bonds were not found to dissociate to generate acetate species as evidenced by the low acetic acid yield (Figure 10) and high-temperature HCN desorption (Figure 9). Rather this indicates that, at the temperature when the $\mathrm{C}-\mathrm{C}$ bond cleaves, both oxygen atoms in glycine may adsorb on the surface.

In addition to $\mathrm{CO}_{2}$ formation, some surface $\mathrm{COO}$ species dissociate to form $\mathrm{O}_{(\text {ads })}$ and $\mathrm{CO}$ (Figures 7 and 9). $\mathrm{CO}$ transfers to threefold hollow surface sites and becomes stabilized and desorbs at $\sim 480 \mathrm{~K}$. At all the glycine coverages, the $\mathrm{CO}_{2}$ (44 amu) desorption peak intensity is roughly equal to that of $\mathrm{CO}$, indicating the branching ratio for $\mathrm{CO}_{2}$ formation and dissociation to form $\mathrm{CO}$ and $\mathrm{O}_{(\text {ads })}$ is close to unity. Similar results have been found previously on $\operatorname{Pt}(111) .{ }^{17}$

Finally, some comments on $\mathrm{H}_{2}$ formation (Figure 7) are warranted. There are three possible sources of atomic hydrogen. The first is hydrogen adsorption from the background, second, the conversion of glycine to glycinate, and third, further decomposition of surface nitrogen-containing species after $\mathrm{C}-\mathrm{C}$ bond scission. The situation is even more complicated since hydrogen adsorbs both on and below the Pd(111) surface. ${ }^{29}$ At glycine coverages below $1 \mathrm{ML}$, the line shapes of $\mathrm{H}_{2}$ (2 amu) desorption profiles are quite similar, displaying three desorption states at 370, 420, and $540 \mathrm{~K}$. At coverages above $1 \mathrm{ML}$, the line shapes change markedly. Apparently the adsorption geometry of glycine molecules below and above $1 \mathrm{ML}$ is quite different.

\section{Conclusions}

Glycine adsorbs strongly on the clean $\operatorname{Pd}(111)$ surface and into second and subsequent layers, where the bare surface coverage is monitored using ${ }^{13} \mathrm{CO}$ titrations. This allows the glycine coverage to be measured as a function of dose and indicates that the first layer saturates after a total of about three monolayers of glycine have been deposited. XPS results suggest that essentially all of the glycine adsorbs into the first layer in its zwitterionic form, whereas condensation into second and subsequent layers contain both zwitterionic and neutral glycine, with about $20-30 \%$ being neutral depending on the total coverage. Molecular glycine desorbs from the multilayer between 336 and $363 \mathrm{~K}$, depending on coverage. A small portion of glycine desorbs molecularly from the first layer, with the remainder undergoing thermal decomposition. This occurs almost exclusively by $\mathrm{C}-\mathrm{C}$ bond scission, with the fragments desorbing as $\mathrm{CO}_{2}$ and $\mathrm{CO}$ from the $\mathrm{COO}$ moiety, and as methylamine or $\mathrm{HCN}$ from $\mathrm{H}-\mathrm{C}-\mathrm{NH}_{2}$.
Acknowledgment. We gratefully acknowledge support of this work by the U.S. Department of Energy, Division of Chemical Sciences, Office of Basic Energy Sciences, under Grant No. DE-FG02-03ER15474.

\section{References and Notes}

(1) Stacchiola, D.; Burkholder, L.; Tysoe, W. T. J. Am. Chem. Soc. 2002, 124, 8984.

(2) Lee, I.; Zaera, F. J. Phys. Chem. B 2005, 109, 12920.

(3) Stacchiola, D.; Burkholder, L.; Zheng, T.; Weinert, M.; Tysoe, W. T. J. Phys. Chem. B 2005, 109, 851.

(4) Atanasoska, L. L.; Buchholz, J. C.; Somorjai, G. A. Surf. Sci. 1978, $72,189$.

(5) His, A.; Liedberg, B.; Uvdal, K.; Tornkvist, C.; Bodo, P.; Lundstrom, I. J. Colloid Interface Sci. 1990, 140, 192.

(6) Barlow, S. M.; Kitching, K. J.; Haq, S.; Richardson, N. V. Surf. Sci. 1998, 401, 322

(7) Hasselstrom, J.; Karis, O.; Weinelt, M.; Wassdahl, N.; Nilsson, A.; Nyberg, M.; Pettersson, L. G. M.; Samant, M. G.; Stohr, J. Surf. Sci. 1998 407, 221.

(8) Zhao, X. Y.; Gai, Z.; Zhao, R. G.; Yang, W. S.; Sakurai, T. Surf. Sci. 1999, 424, L347.

(9) Efstathiou, V.; Woodruff, D. P. Surf. Sci. 2003, 531, 304.

(10) Rankin, R. B.; Sholl, D. S. J. Phys. Chem. B 2005, 109, 16764.

(11) Liedberg, B.; Lundstrom, I.; Wu, C. R.; Salaneck, W. R. J. Colloid Interface Sci. 1985, 108, 123.

(12) Holtkamp, D.; Jirikowsky, M.; Kempken, M.; Benninghoven, A. J. Vac. Sci. Technol., A 1985, 3, 1394.

(13) Zhao, X.; Yan, H.; Zhao, R. G.; Yang, W. S. Langmuir 2002, 18, 3910.

(14) Lange, W.; Jirikowsky, M.; Benninghoven, A. Surf. Sci. 1984, 136, 419.

(15) Stewart, S.; Fredericks, P. M. Spectrochim. Acta, Part A 1999, 55, 1641.

(16) Ernst, K. H.; Christmann, K. Surf. Sci. 1989, 224, 277.

(17) Lofgren, P.; Krozer, A.; Lausmaa, J.; Kasemo, B. Surf. Sci. 1997, $370,277$. 383.

(19) Zhao, X.; Yan, H.; Tu, X.; Zhao, R. G.; Yang, W. S. Langmuir 2003, 19, 5542

(20) Zhao, X.; Rodriguez, J. Surf. Sci. 2006, 600, 2113.

(21) Kaltchev, M. G.; Thompson, A.; Tysoe, W. T. Surf. Sci. 1997, 391 145.

(22) Hoffmann, F. M. Surf. Sci. Rep. 1983, 3, 107.

(23) NIST Chemistry Webbook. http://webbook.nist.gov/chemistry/.

(24) Holtkamp, D.; Lange, W.; Jirikowsky, M.; Benninghoven, A. Appl. Surf. Sci. 1984, 17, 296.

(25) Christmann, K.; Ertl, G.; Pignet, T. Surf. Sci. 1976, 54, 365

(26) Haley, R. D.; Tikhov, M. S.; Lambert, R. M. Catal. Lett. 2001, 76, 125.

(27) Jirikowsky, M.; Holtkamp, D.; Klusener, P.; Kempken, M.; Benninghoven, A. Surf. Sci. 1987, 182, 576.

(28) Chen, J. J.; Winograd, N. Surf. Sci. 1995, 326, 285.

(29) Stacchiola, D.; Tysoe, W. T. Surf. Sci. 2003, 540, L600. 